\title{
1 Coastal winds and larval fish abundance indicate a recruitment mechanism for southeast
}

\section{Australian estuarine fisheries}

3 Hayden T. Schilling ${ }^{1,2 *}$, Charles Hinchliffe ${ }^{2}$, Jonathan P. Gillson ${ }^{3}$, Anthony Miskiewicz ${ }^{2,4}$, lain M.

4 Suthers ${ }^{1,2}$

1. Sydney Institute of Marine Science, Chowder Bay Road, Mosman, 2088, Australia

2. Centre for Marine Science \& Innovation, UNSW Australia, 2052 Australia

3. The Centre for Environment, Fisheries and Aquaculture Science, Pakefield Road, Lowestoft, NR33 OHT, United Kingdom

4. Australian Museum, College St., Sydney 2000, Australia

$11 *^{*}$ Corresponding author: $\underline{\text { h.schilling@unsw.edu.au }}$ 


\section{Abstract}

15 Coastal winds transport water masses and larval fish onshore or offshore which may influence

16 estuarine recruitment, yet our understanding of the mechanism underlying this relationship is

17 limited. Here, we combine datasets from a historical database of larval fish off southeast Australia

18 with a high-resolution atmospheric reanalysis model to show that normalised abundance of coastally

19 spawned larvae increased with weak to moderate upwelling favourable winds 14 days prior to

20 sampling. The increase in abundance may reflect increased nutrient and plankton availability for

21 larval fish. Normalised larval abundance decreased following strong upwelling favourable winds but

22 increased after onshore (downwelling favourable) winds, due to wind-driven transport. By

23 combining a commercial estuarine fisheries catch-rate dataset (4 species, 8 estuaries, 10 years) and

24 the high-resolution atmospheric reanalysis model, we show that negative effects of upwelling

25 favourable winds during the spawning period can be detected in lagged estuarine commercial

26 fisheries catch rates (lagged by $2-8$ years depending on species' growth rates), potentially

27 representing the same mechanism proposed for larval fish. Upwelling favourable winds in the southeast Australian region have increased since 1850 while onshore winds have decreased, which may reduce larval recruitment to estuaries. Coastal winds are likely an important factor for estuarine recruitment in the southeast Australian region and future research on the estuarine recruitment of fish should incorporate coastal winds.

33 Keywords: larval fish, retention, wind driven upwelling, fisheries production, Harald Dannevig, 34 downwelling, estuarine recruitment 


\section{Introduction}

Strong year classes of marine fish have long interested fisheries oceanographers, with many studies attempting to better understand the drivers of variability in population dynamics (Houde, 2008). Previous studies have linked strong year classes with abiotic and biotic factors during the larval period, with hypotheses either focusing on increased growth or reduced mortality resulting in a higher recruitment (Garvine et al., 1997; Helbig and Pepin, 1998; Pepin, 2016). Some of the key factors influencing recruitment include the biomass of the spawning stock, location and timing of spawning, the vertical distribution of eggs and larvae and upwelling generated productivity. The spawning stock biomass (SSB) is the basis for recruitment success (Cury et al., 2014) and in combination with fecundity, egg viability and sex ratio, determines the number of eggs and larvae which subsequent stochastic processes act upon to shape recruitment (Kell et al., 2016).

Stochastic processes are often more influential than SSB due to the high variability in mortality and subsequent recruitment (Szuwalski et al., 2015). The location and timing of spawning events is also important for overall recruitment, with seasonal and interannual variations in oceanography often shaping dispersal and potential recruitment (Ciannelli et al., 2015; Schilling et al., 2020). As larvae have limited swimming potential in their early stages (hence oceanographic driven dispersal), larvae which can control their vertical positioning often exploit vertical variation in cross-shelf flow on continental shelves to remain near favourable areas for juvenile habitat, potentially increasing recruitment (Hare and Govoni, 2005; Ospina-Alvarez et al., 2018).

Productivity, which is often generated by upwelling (Everett et al., 2014), is often suggested as a driver of faster growth in fish larvae through the intermediate production of phytoplankton and zooplankton thereby reducing mortality from predation, as the larvae increase in swimming ability (Anderson, 1988; McFarlane and Beamish, 1992), and increasing recruitment (Bailey and Houde, 1989). On the other hand, upwelling can also have negative effects in some circumstances due to offshore transport away from suitable recruitment habitat. While the influence of upwelling has been clearly demonstrated in some regions including the southern Benguela upwelling region (Wilhelm et al., 2005) and the Northeast Atlantic (Santos et al., 2004), this process is likely region specific and remains uncertain in many regions, including the southwest Pacific.

The coastal waters of eastern Australia are dominated by the East Australian Current (EAC; Oke et al., 2019). The EAC generally transports larvae poleward along a narrow continental shelf $(<30 \mathrm{~km})$ to coastal and estuarine nursery habitats (Roughan et al., 2011; Schilling et al., 2020). Together with the EAC, onshore winds are an important driver of upwelling and downwelling 
through Ekman transport mechanisms (Roughan and Middleton, 2002; Schaeffer et al., 2013, 2014).

Wind is an important driver of cross-shelf flows in the area (McClean-Padman and Padman, 1991; Middleton et al., 1996). Winds from the northeast (NE) blow along the coastline, promoting offshore Ekman transport and upwelling of cold nutrient-rich water along the coast, while winds from the southeast (SE), promoting onshore transport and downwelling (Griffin and Middleton, 1992; Middleton et al., 1996).

It was first hypothesised that onshore winds may be affecting nearshore retention and potentially driving fluctuations in commercial catches in southeastern Australian estuaries in the early $20^{\text {th }}$ century (Dannevig, 1907; Suthers et al., 2020). Dannevig (1907) hypothesised that onshore winds reduced unfavourable advection of fish eggs and larvae, retaining them nearer the coast and therefore increasing recruitment to estuarine fisheries. When testing this hypothesis, Dannevig (1907) found a positive correlation between estuarine commercial catch rates and onshore winds lagged by three or four years (Suthers et al., 2020). Since the inception of this hypothesis, many studies have shown relationships between wind and juvenile recruitment with the effects largely being system specific (Nelson et al., 1977; Caputi et al., 2001; Takeshige et al., 2013; Wilson and Laman, 2021), likely due to complex estuary specific recruitment processes (Boehlert and Mundy, 1988).

The winds in many of the world's coastal upwelling systems are being altered due to climate change, resulting in both increases (California, Benguela and Humboldt systems) and decreases (e.g. Iberian system) in upwelling favourable winds (Sydeman et al., 2014). Changing winds are likely to have a range of effects including enrichment of waters, regional changes in stratification and basinscale changes in thermocline structure, all of which may influence the productivity of local fisheries (Bakun et al., 2010). Concerns have been expressed with regards to changing coastal winds altering upwelling regimes which provide important nutrients to ecosystems (Bakun and Weeks, 2008; Bakun et al., 2010; Sorte, 2013). In addition to changes in nutrient supply, variation in upwelling patterns may also affect the advection and recruitment of larval fish to estuaries.

Estuary specific characteristics also contribute to variation in commercial catch rates through both short term catchability effects and longer term productivity differences among estuaries. Within estuarine environments, fish and fisher behaviour can change in response to external effects such as weather or freshwater flow (Gillson, 2011). Key estuarine fisheries families such as Sparidae have been shown to reverse their diel behaviour patterns following heavy rain (Payne et al., 2013), with the catch rates of many species differing between drought and nondrought conditions (Gillson et al., 2009). Within eastern Australia, it has been demonstrated that 
there are consistent differences in hydrology and fisheries production between types of estuaries defined by their geomorphology (Pease, 1999; Roy et al., 2001). When investigating variation in estuarine fisheries production, potentially due to larval recruitment effects, it is therefore necessary to control for differences originating from differences in freshwater flow or estuarine type.

In the present study, we test the original hypothesis of Dannevig (1907) using both larval fish abundance and commercial fisheries data. To evaluate offshore and onshore winds (upwelling favourable and downwelling favourable respectively) as a driver of estuarine fisheries production in southeast Australia, model-based estimates of surface wind were first compared to normalised abundances of 132 taxa of coastally spawned fish larvae (1990 - 2016), and then to estuarine fishery catches (4 species, 8 estuaries, July 1997 - June 2007). Our present study extends the idea of Dannevig (1907) by investigating both larval fish and commercial catch data to test three specific aims. Firstly, we examine whether coastal winds influence the abundance of coastally spawned larval fish near the coast. Secondly, we evaluate whether the same winds during the spawning period influence commercial fisheries harvest when lagged by an appropriate growth period for each species. Finally, we explore changes in the upwelling and downwelling (onshore) favourable winds since 1850. We expect that coastally spawned larval abundance will be greater during periods of onshore winds. If the onshore transport of coastal fish larvae does occur during downwelling favourable winds, then the effects of this retention should result in increased larval supply to estuaries, and assuming juvenile fish are resident in estuaries until size of capture, may result in a detectable effect on commercial fisheries catch rates.

(1)


127 To provide a consistent estimate of winds, we used the wind speed and direction data from the

128 Australian Bureau of Meteorology Atmospheric high-resolution Regional Reanalysis for Australia

129 (BARRA; Su et al., 2019, 2020). This re-analysis product provides hourly wind speeds at a $12 \mathrm{~km}$ resolution over the Australian domain with downscaled $1.5 \mathrm{~km}$ resolution within several subdomains between 1990 and 2019. For all analyses in the present study, we used near-surface (10 m) wind data from the $1.5 \mathrm{~km}$ resolution data from within the Eastern New South Wales subdomain (Su et al., 2020). This $1.5 \mathrm{~km}$ reanalysis model demonstrates high agreement with observations, with higher skill than the $12 \mathrm{~km}$, particularly in coastal areas (Su et al., 2020).

To provide a long-term context, we also used wind speed and directions from the $20^{\text {th }}$ Century Reanalysis V2c data collated by the NOAA/OAR/ESRL PSD (www.esrl.noaa.gov/psd/), which provides three-hourly wind speed and direction data from 1850 to 2014 at a resolution of $\approx 200 \mathrm{~km}$ (Compo et al., 2015). As both wind products are reanalysis datasets, the models are constrained by observed values.

142 To investigate the response of larval fish abundance to wind, we used data from the Australian 143 Integrated Marine Observing System (IMOS) Larval Fish Database (Smith et al., 2018). Fish larvae 144 were all collected from the top 150m of water using horizontal and oblique tows from variety of 145 plankton nets with a $300-500 \mu \mathrm{m}$ mesh size (see Smith et al. (2018) for full dataset description and 146 Table S1 for a summary of the samples included in the current analysis). Each sample refers to a single plankton tow and the abundance of each taxon collected. While the database contains abundance information for 218 taxa collected over 12 research projects (1983 - 2016; Smith et al., 2018), the present study selected only seven of these projects that matched the temporal resolution of the wind data (1990 - 2016; Table S1) for analysis. coastally spawned fish larvae could be detected at the commercial fisheries scale, we used an 
estuarine catch-per-unit-effort (CPUE) dataset from eastern Australia (Gillson et al., 2009). This dataset consisted of ten years of monthly CPUE data (combined to annual values; July 1997 - June 2007) from gillnet fisheries in located inside eight estuaries along the east Australian coast (Roy et al., 2001; Table S1). An extensive description of the dataset is given in Gillson et al. (2009). Briefly, these CPUE data were derived from monthly catch (kg of harvest) and effort (fishing days) for four fish species; yellowfin bream (Acanthopagrus australis; Sparidae), sea mullet (Mugil cephalus; Mugilidae), dusky flathead (Platycephalus fuscus; Platycephalidae) and sand whiting (Sillago ciliata; Sillaginidae). These fish species represent the dominant contribution to both commercial and recreational estuarine fisheries harvest. All four of these species are known to spawn in nearshore coastal waters before juveniles recruit to estuaries (spawning seasons and references detailed in Table 1). Sand whiting and dusky flathead larvae are usually found at deeper depths (15-50 m) while sea mullet larvae are found in surface waters (Collins and Stender, 1989). Yellowfin bream larvae are found equally throughout the top $30 \mathrm{~m}$ of the water column, with some larvae found up to $70 \mathrm{~m}$ deep (Gray, 1993; Gray et al., 2019). Luderick (Girella tricuspidata; Girellidae) was in the original data (Gillson et al., 2009), but was not included in the present study due to the variable spawning periods between populations in this region (Gray et al., 2012). While CPUE is often not considered a robust measure of fish abundance (Richards and Schnute, 1986; Harley et al., 2001; Haggarty and King, 2006), for our purpose gillnet CPUE provided a measure of fisheries catch ( $\geq 80 \mathrm{~mm}$ mesh size) using a passive gear type to assess the impacts of variation in recruitment on catch rates and presented the most consistent method available from which an index of abundance could be inferred (Gillson et al., 2009). Due to reporting requirements at the time, effort represents total gillnet effort on monthly timescale, undifferentiated by species. There is some seasonality to the fishing effort which is generally higher in winter months, corresponding to increased CPUE for flathead and bream, suggesting fishers may target bream and flathead in winter months. As we analysed our data on an annual time scale and there are no changes in annual effort (Figure S3), the seasonality is consistent between years.

\section{Data Preparation}

All data preparation and analysis was conducted using R v4.0.2 (R Core Team, 2020).

\section{Wind Data}

Wind speed and direction data were extracted based upon the specific dates and locations of samples (larval fish or estuary locations) using the R packages 'tidyverse' (Wickham, 2017), 'raster' (Hijmans, 2019), 'ncdf4' (Pierce, 2019) and 'RedaS' (Hatzinger et al., 2015). For each sample, the 
wind direction and speed were taken as the mean of 10 pixels $(15 \mathrm{~km} \times 15 \mathrm{~km})$ centred over the sample latitude/longitude.

To investigate the interaction between offshore advection/upwelling favourable (NE) and retention/downwelling favourable (SE) winds, we separated the onshore winds in eastern Australia into SE and NE components resulting in two variables. The SE and NE components of wind are most relevant to the transport of larvae. To calculate the magnitude of wind in a particular direction (SE or NE winds) from the known direction and speed, we converted the wind direction to radians and applied a sine function, taking the absolute value to create an effect size for wind displacement. This can be interpreted as the net movement of air moving along a specified axis (NE or SE). If the wind was directly from $45^{\circ}$ (for NE winds; $135^{\circ}$ for SE), then it was a full effect (1); but if it was at a slight angle, then it was reduced $(<1)$ according to the sine function.

$$
E=|\sin (r(d+a))|
$$

Where $E=$ effect size for the wind displacement, $r=$ a function to convert direction wind is going towards to radians, $d=$ direction wind is going towards $\left({ }^{\circ}\right), a=45^{\circ}$ for NE calculation or $135^{\circ}$ for $\mathrm{SE}$ calculation.

The effect size was then multiplied by the wind speed to get the displacement in each direction per hour and -1 to account for the data being direction towards and ensure offshore winds were negative.

$$
D=E \times s \times-1
$$

Where $D=$ displacement $\left(\mathrm{km} \mathrm{h}^{-1}\right)$ and $s=$ wind speed $\left(\mathrm{km} \mathrm{h}^{-1}\right)$.

Displacement values were then summed to generate a total net displacement $(\mathrm{km})$ over the time span of interest. A positive net displacement means that a greater amount of air moved onto the coast than off the coast during the time period. The use of net displacement rather than other methods aligns with the original work of Dannevig (1907) and Suthers et al. (2020) while presenting a similar metric to Schlaefer et al. (2018). Henceforth, references to upwelling favourable winds (NE winds) or downwelling favourable winds (SE winds) refer to net displacement of air in either upwelling or downwelling favourable directions. While we are calculating wind displacement, rather than direct upwelling or downwelling (Ekman transport), wind is a key driver of upwelling in this region (Schaeffer et al., 2013). 
217 We subset the larval fish abundance data to include samples taken on the continental shelf $(\leq 1000$

218 m bathymetry; Figure 1) between $30-36^{\circ} \mathrm{S}$ for the period 1990 to 2016 (to match wind data

219 availability). In order to investigate recruitment mechanisms affecting all coastally spawned fish,

220 within each larval fish sample we focused only on taxa known to spawn coastally in this region (Table

221 S2; Neira et al., 1998, Miskiewicz Unpublished Data). While this may miss some species-specific

222 effects, we are assuming that coastally spawned taxa will respond in similar ways prior to their

223 swimming ability improving with larval development, which facilitates movement from coastal waters into estuarine nursery habitats. To avoid any one taxon dominating the abundance of coastal larvae, the abundance of each taxon was normalised (i.e. the abundance of each family summed to 1) by transposing the dataset and using the 'normalize.rows()' function from the 'vegetarian' $R$ package (Charney and Record, 2012). This created a relative abundance measure and ensured that each taxon had equal weighting during subsequent analysis, removing species specific effects. The normalised abundance of each taxon was summed together to create a single metric for analysis. Following normalisation, the normalised relative coastal abundance across all samples had a mean of 0.07 (SD = 0.11), with a maximum of 1.48 and the mean abundance was stable between sampling projects (Figure S1). By using the relative abundance of a suite of species, the possibility exists that some individual species-level effects may be missed, but during the larval stage (and without size information) we are assuming that swimming ability is poor and that all species will respond similarly to coastal winds. The larval fish sampling in Smith et al. (2018) was spatially inconsistent and in this region larval abundance is also generally higher in shallower areas (Hinchliffe et al., 2021). Therefore, to control potential bias, we calculated the distance $(\mathrm{km})$ to the nearest point of the Australian mainland for each sample to use as a covariate during modelling.

To separate the effects of advection from upwelling favourable (NE) winds and onshore transport from downwelling favourable (SE) winds on larval fish abundance, the net air displacement for upwelling favourable and downwelling favourable winds for each larval fish sample was calculated by summing the hourly displacement measurements of the previous 14 days. This time period was selected to quantify both potential upwelling and retention against the coast as there are often lagged effects on larval abundance through physical transport and nutrient enrichment (Dalley et al., 2002; Ings et al., 2008). While larval transport can happen over short periods of time, 14 days is the approximate period it takes for upwelling to generate secondary production (increased phytoplankton and zooplankton) in this region and therefore provide a potentially favourable environment for fish larvae to develop (Baird et al., 2006). 
252 For our investigation, we aggregated all monthly data to an annual scale (July - June). Over the ten-

253 year period, there were no major regulation or fisher behaviour changes within this fishery and both

254 total catch and CPUE fluctuated despite relatively stable fishing effort within each estuary (Figures S2 - S4). We therefore proceeded under the assumption that fluctuations in annual CPUE may be a reliable proxy for fish abundance (Gillson et al., 2009).

To investigate the effects of upwelling and downwelling favourable winds during the spawning periods of the commercially important fish species and the effects on lagged annual CPUE, onshore winds were calculated for each estuary (located $0.15^{\circ} \mathrm{E}$ of the estuary mouth; Figure 1), centred, and scaled according to the above method with upwelling (NE) and downwelling (SE) favourable components. For all estuaries, there were years of relatively high and low winds (Figures S5 \& S6). The net air displacement during the spawning period was determined by identifying the spawning periods of each species from published literature (Table 1). Rather than exploring multiple lags, we identified lags a priori by using the modal age of these species caught by gillnets in these estuaries (Gray et al., 2015). The modal age is the age at which the species are fully recruited to the fishery, removing any effect of gear selectivity. This age was then used to lag the spawning period winds to correspond to the most abundant (modal) age class, which are therefore most likely to show an effect of the onshore winds if they were influencing larval recruitment. As drought has previously been shown to be an important driver for this CPUE dataset (Gillson et al., 2009), we included drought as the number of months each estuary was 'drought declared' during each 12-month CPUE period based on the New South Wales Department of Primary Industries drought situation maps. Our dataset also contained three types of estuaries (barrier river, drowned river valley $\&$ barrier lagoon) which might have differing responses to drought due to their different flushing schemes (Roy et al., 2001).

Statistical Analysis 
above. A total of 60 larval fish samples (4\%) contained no (zero) coastally spawned larvae. Rather than remove these samples we used a two-stage gamma hurdle model to test the effects of upwelling favourable (NE) and downwelling favourable (SE) winds on larval fish abundance. This gamma hurdle model first analyses all the data in a presence-absence method using a Bayesian binomial model with a logit link. This is followed by a Bayesian generalised linear mixed model with a gamma error distribution using a log link for the presence only data because the abundance data had a continuous, positively skewed, distribution. The model included the fixed effects of downwelling favourable winds, upwelling favourable winds and distance from the coast $(\mathrm{km})$ as well as interaction terms and separate quadratic terms for both downwelling and upwelling favourable winds with interactions with distance-to-coast. Both linear and quadratic terms for the downwelling and upwelling favourable winds were included in the models because it was hypothesised that the winds would have a disproportionate effect on larval fish abundance at low or high speeds, hence a non-linear fit may be appropriate. Distance-to-coast was included as a covariate to control for the natural increase in larval abundances closer to the Australian mainland (Hinchliffe et al., 2021). Distance-to-coast, upwelling favourable (NE) and downwelling favourable (SE) winds were centred and standardised to assist the model fitting process and increase interpretability of the model coefficients (Schielzeth, 2010). This means a wind of 0 is interpreted as moderate (i.e. the mean) while positive values are stronger winds and negative values are weaker than the mean.

Since the Australian IMOS Larval Fish database includes data from a variety of projects which used slightly different sampling methodologies (Smith et al., 2018), the model also included a random intercept effect for Project. As each Project occurred in a discrete time period, this random effect also controls for any temporal inconsistencies such as a traditional year effect. The use of normalised larval abundances also creates a more consistent dataset despite the differences in sampling over time. The fitted model thus had the form:

$$
\begin{gathered}
\text { Abund }_{i t}=\left\{\begin{array}{l}
0 \quad \text { with probability } p \text { and } \\
\operatorname{Gamma}\left(\mu_{i, t}, \varphi\right) \text { with probability } 1-p
\end{array}\right. \\
\eta_{i, t}=\alpha+\text { Up_Winds }_{i, t}+U p_{-} \text {Winds }_{1, t}^{2}+\text { Down_Winds }_{i, t}+\text { Down_Winds }_{1, t}^{2}+U p_{-} \text {Wind }_{i, t} \\
* \text { Down_Winds } s_{i, t}+\text { Distance_to_Coast }_{i, t}+v_{t}
\end{gathered}
$$

Where the probability that the relative abundance of coastally spawned larvae (Abund) is 0 was modelled as logit $(p) ; \alpha$ is a constant intercept; Variables relate wind and distance-to-coast variables to the abundance of coastally spawned larvae in sample $i$ from project $t .{ }^{*}$ represents an interaction term in the model. Abund was modelled as Gamma distributed with mean $\mu_{i, t}$ fitted via a log link 
with linear predictor $\eta_{i, t}$, and shape parameter $\varphi . v_{t}$ is a random intercept by project with mean 0 and variance $\sigma_{t}^{2}$.

Model parameters were estimated by MCMC using Stan (Carpenter et al., 2017) using the function brm() of R package 'brms' (Bürkner, 2018). Four parallel MCMC chains were run for 10,000 iterations (5,000 warm up and 5,000 samples each chain) and all parameter estimates were presented with their $95 \%$ Bayesian credible intervals $(\mathrm{Cl})$. Convergence was assessed by visually examining MCMC trace plots and assessment of the Gelman-Rubin statistic (Brooks and Gelman, 1998). The overall model fit was assessed by extracting residuals from the model and generating standard Pearson's residual vs fitted plots and normal quantile plots, following the model checking procedure of Gillson et al. (2020). The model was considered stable as the chains were well mixed (Figure S7) the Gelman-Rubin test statistic $<1.01$ for all parameters. The shape and hurdle parameter estimates did not overlap zero (shape $95 \% \mathrm{Cl}: 0.54-0.62$, hu $95 \% \mathrm{Cl}$ : $0.13-0.17$ ), thereby justifying the added model complexity in this case. There was some deviance from model fit (Figure S8), particularly in the tails of the dataset but due to the large number of samples and appropriateness of the gamma hurdle structure we proceeded with the analysis.

Default weakly informative priors were used for all parameters: improper flat priors over the reals for covariate effects, Student- $t(\mu=-3.1, \sigma=2.5, v=3)$ for the intercept, Student- $t(\mu=0, \sigma=2.5, v=$ $3)$ for the standard deviation terms, $\operatorname{Gamma}(0.01,0.01)$ for $\varphi$ and $\operatorname{logistic}(0,1)$ for the zero Abund probability parameter. To visualise the effects of the model predictors, marginal effects were calculated using the 'ggeffects()' function in the 'ggeffects' R package (Lüdecke, 2018).

\section{Effect of wind on estuarine fisheries catch rates}

A Bayesian linear mixed model with gaussian error distribution was used to assess the effects of coastal winds on annual CPUE. The model included fixed effects of downwelling favourable winds, upwelling favourable winds (NE), drought months and estuary type, interactions between drought months and estuary type, upwelling and downwelling favourable winds as well as quadratic terms for both upwelling and downwelling favourable winds. To investigate the overall effect of onshore winds on annual CPUE and incorporate the dependency structure among observations from the same estuary or species, we used estuary as a random intercept and species as a random slope effect as part of a Bayesian linear mixed model. This controls for our data coming from the same eight estuaries over a ten-year period with species crossed with estuary. The random intercept lets each estuary have different overall level of production while the random slope effect lets each 
species respond differently to the environmental variables. Using the annual CPUE as the response variable, the linear mixed model was fit and assessed using the same method described above for the larval fish analysis. The fitted model thus had the form:

$$
\begin{gathered}
\text { CPUE }_{\text {jns }}=\text { UpWind }_{\text {jns }}+\text { DownWind }_{\text {jnsit }}+\text { UpWind }_{\text {jns }} \times \text { DownWind }_{j n s}+\text { UpWind }_{j n s}^{2} \\
+ \text { DownWind }_{\text {jns }}^{2}+\text { EstuaryType }_{j n s}+\text { DroughtMonths }_{j n s} \\
+ \text { EstuaryType }_{\text {jns }} \times \text { DroughtMonths }_{\text {jns }}+\text { Estuary }_{n} \times \text { Species }_{S} \\
\text { Estuary }_{n} \sim N\left(0, \sigma_{n}\right) \\
\text { Species }_{s} \sim N\left(0, \sigma_{s}\right)
\end{gathered}
$$

Where $C P U E_{j n s}$ is the $j$ th CPUE observation in Estuary $n$ for Species s. Estuary ${ }_{n}$ is the random intercept and Species $_{S}$ is the random slope effect. UpWind is the standardised upwelling favourable winds, DownWind is the standardised downwelling favourable winds, EstuaryType is the type of estuary an observation was from, DroughtMonths is the number of months of 'declared drought' during the year. Uninformative flat priors were used for all variables except the overall intercept and random intercepts for Estuary and Species. The overall intercept used a Student- $t(\mu=30.8, \sigma=40.3, v=3$ ) and the random intercepts for Estuary and Species both used Student- $t(\mu=0, \sigma=40.3, v=3)$. The CPUE model showed good convergence of chains with Gelman-Rubin test statistic $<1.01$ for all parameters but there was some divergence in model fit towards the tails (Figures S9 \& S10).

\section{Historical Wind Changes}

To investigate whether or not upwelling or downwelling favourable winds have changed over time in southeast Australia, we used the $20^{\text {th }}$ Century Reanalysis V2c dataset (1850-2014; Compo et al., 2015) and calculated upwelling favourable (NE) and downwelling favourable (SE) winds as described above, except net annual displacement was derived by summing all winds during a Gregorian calendar year (centred on Sydney $33.839^{\circ} \mathrm{S} 151.309^{\circ} \mathrm{E}$; Figure 1). To ensure consistency with the high-resolution BARRA model used for the prior analyses, we initially tested the correlation between the BARRA model and $20^{\text {th }}$ Century Reanalysis V2c model using both annual displacement for upwelling favourable (NE) and downwelling favourable (SE) winds for the overlapping years (19902014) centred over Sydney. There was a moderate to high correlation for both upwelling favourable $\left(r=0.599, t_{23}=3.589, P=0.002\right)$ and downwelling favourable $\left(r=0.697, t_{23}=4.658, P<0.001\right)$ winds. We then applied two separate Bayesian linear models with gaussian error distributions for upwelling favourable (NE) and downwelling favourable (SE) winds with year as a fixed effect (flat 
uninformative prior). Initial exploration revealed temporal autocorrelation in the first and second year of the wind time-series data as measured with the 'acf function from the 'stats' $R$ package $(R$ Core Team, 2020). Therefore, wind data from every third year were used in the final analysis to remove the presence of temporal autocorrelation. Bayesian linear models were fit and assessed using the same method described above for the larval fish analysis, with good mixing of chains and model fit (Figures S11 - S14).

For interpretation of all model outputs in this study we used the median posterior estimate for parameters and the $95 \%$ Bayesian $\mathrm{Cl}$. If the $95 \% \mathrm{Cl}$ did not overlap zero, we deemed a parameter important (van der Linden and Chryst, 2017). Conditional (full model) and marginal (fixed factors only) $R^{2}$ values were calculated using the method of Gelman et al. (2019) and implemented in the function 'r2_bayes()' of R package 'performance' (Lüdecke et al., 2020).

For both the larval and CPUE models, sensitivity analyses were performed on the lag times used to assess the robustness of our findings. This involved running the models multiple times while altering the duration of the lag period. For the larval models, we varied the lead up time for winds by $9-20$ days prior to sampling and for the CPUE models we simulated altering the lag by \pm 2 years from the identified modal age. This is important for the CPUE models as there are potential influences in the data due to the harvesting of multiple age classes. As we chose the modal age from gillnet sampling, our original lag should have the strongest effect, and if multiple age classes are present in a sample, 
Results

400

Coastally Spawned Larval Fish

401

A total of 175,112 larval fish from 132 coastal spawning taxa were present in 1,489 observations on

402 the continental shelf between 30 and $36^{\circ} \mathrm{S}$. Examining the winds 14 days prior to sampling revealed

403 evidence of an interaction between distance-to-the-coast, upwelling favourable (NE) wind and

404 downwelling favourable winds (Estimate $=-0.48,95 \% \mathrm{Cl}:-0.85--0.13$; Figure 2). This interaction can be interpreted as upwelling and downwelling favourable winds interact with each other in different ways depending on the distance a sample is taken from the coast. An overall decline in abundance was observed with increasing distance from the coast (Figure 3). Upwelling favourable winds had a nonlinear effect on abundance where when upwelling favourable winds increased from below average to moderate amounts ( 0 on standardised axis), larval abundance increased but then as the winds strengthened further, abundance decreased (Figure 3). This resulted in an optimum threshold where larvae were most abundant following moderate amounts of upwelling favourable wind.

412 Downwelling favourable winds showed a linear positive effect on abundance (Figure 3). Both the 413 upwelling and downwelling favourable wind relationships were strongest near the coast and the relationships became less defined with increasing distance from the coast (Figure S15).

Our 14-day wind model explained a small amount of variance in larval fish abundance (conditional $R^{2}$ $=0.059$, marginal $\left.R^{2}=0.044\right)$, and the sensitivity analysis of the wind lead up times in the larval fish model showed that estimates of most effect sizes did not clearly change between $9-21$ days lead up (overlapping error bars; Figure S16). Two changes were evident in the sensitivity analysis: 1) the interactions between upwelling favourable winds and downwelling favourable winds became

420 inconsequential when a 9-12 day lag was tested (error bars overlaps 0 ); and 2) the effect size of 421 interaction between upwelling favourable winds, downwelling favourable winds and distance-tocoast became smaller at a 9 day lag, although still remained important and negative.

The multi-species model performed well (conditional $R^{2}=0.822$, marginal $R^{2}=0.506$ ) and showed strong evidence for a negative effect of upwelling favourable winds during the spawning period on

427 CPUE (Estimate: -230.48, 95\% Cl: -374.58 - -85.05; Figures 4 \& 5). There was no evidence of any 428 effect from downwelling favourable winds on CPUE (Estimate: $-88.62,95 \% \mathrm{Cl}$ : $-227.90-50.63$;

429 Figure 4). 
430 Aside from the wind effects, there was evidence of a positive effect of drought on CPUE (Estimate =

$4318.16,95 \% \mathrm{Cl}: 4.56-11.70$ ) although this effect was variable depending on estuary type. Barrier

432 Lagoon estuaries had a more positive response to drought compared with Barrier Rivers and

433 Drowned River Valleys (Figure S17).

434 The sensitivity analysis of the wind lag times in the CPUE model showed that altering the lag times

435 only influenced the wind effects with the standard error of all other estimates overlapping the lag

436 change 0 estimates for all the lags considered (Figure S18). When the lag was shortened by one year

437 or increased by two years, there was an interaction evident between upwelling favourable winds

438 and downwelling favourable winds (Figure S18). The effect size of upwelling favourable winds varied

439 with lag time. The effect became inconsequential when the lag was shortened by two years while a 1

440 year longer lag had a stronger effect on CPUE compared to a 1 year shorter lag. The effect of altering

441 the lag time of downwelling favourable winds was more variable with a non-linear pattern occurring

442 if the lag was increased by two years. If the lag was reduced by 1 year, the effect of downwelling

443 favourable winds became inconsequential.

444 Between 1850 and 2014, there was clear evidence of an increase in upwelling favourable winds

445 (Estimate of annual change: 52.86, 95\% Cl: 19.00 - 85.59; Figure 6) and a decline in onshore

446 transport causing downwelling favourable winds (Estimate of annual change: $-40.93,95 \% \mathrm{Cl}:-78.18$

$447-3.71$; Figure 6). The upwelling favourable winds shifted from a negative net displacement to a

448 positive net displacement (Figure 6), meaning that along the $45^{\circ}$ axis the prevalence of upwelling

449 favourable winds has increased over time. The downwelling favourable winds remained net positive

450 but declined to approximately half of their initial levels (Figure 6). 
By combining three datasets from a larval fish database, a high-resolution wind re-analysis model and commercial CPUE time-series data, we have demonstrated that coastal winds may influence the near-shore abundance of coastally spawned taxa (Figures $2 \& 3$ ), potentially resulting in detectable effects on commercial fisheries catch rates (Figures $4 \& 5$ ). While we initially expected samples collected following strong onshore winds to have the highest abundance of coastal larvae, we found both upwelling and downwelling favourable winds are important for fish larvae. Moderate amounts of upwelling favourable winds potentially increased planktonic production (Armbrecht et al., 2014), although above average upwelling favourable winds negatively affected coastal larvae abundance, perhaps due to offshore advection. Strong downwelling favourable winds had a positive influence on the abundance of coastally spawned larvae, likely driving onshore transport which may facilitate estuarine recruitment (Agostini and Bakun, 2002). Using lagged winds from each species' spawning season, we showed a detectable negative effect of strong upwelling favourable winds on CPUE, possibly due to the advection of larvae away from favourable habitat. This was a similar effect to that observed in the larval fish with strong upwelling favourable wind being correlated with low relative abundance of coastal larvae. We found no evidence of the hypothesised positive effect of downwelling favourable winds in the CPUE analysis. The high variance explained in the CPUE models (conditional $R^{2}=0.82$ ) in the present study indicates that incorporating wind from the spawning period into future recruitment models might improve forecasts of estuarine fisheries CPUE. This is important as we have demonstrated that coastal winds have changed since 1850 and are expected to continue changing in the future (Bakun et al., 2010; Sydeman et al., 2014).

\section{A proposed recruitment mechanism}

474 We showed a negative effect of upwelling favourable wind on larval fish abundance when it was

475 above average strength. This is likely caused by offshore transport as strong upwelling drives

476 advection away from the coast and juvenile estuarine and nearshore habitat. It is also recognised

477 that over an approximate 14 day cycle, upwelling can generate increased nutrients and chlorophyll

478 at the surface which may in turn flow into the lower trophic levels (Gasol et al., 1997; Buesa, 2019).

479 This upwelling may increase prey availability for larval fish, thereby increasing growth and survival

480 rates (Zenitani et al., 2007). Onshore transport from downwelling favourable winds is important as it

481 retains larvae near the coast. Based upon previous research, the positive effects of this retention are 
most visible after upwelling preconditions the ecosystem with nutrients, thereby creating a favourable environment near juvenile habitat (Rykaczewski and Checkley, 2008).

Our sensitivity analysis showed a consistently positive effect of downwelling favourable winds regardless of lag time. We believe this supports our hypothesis that onshore transport may increase recruitment into estuaries by larval fishes as they are geographically closer and stochastic dispersal will be reduced (Bruno et al., 2018).

\section{Commercial Estuarine Fisheries}

Consistent with Dannevig's (1907) observation, we found coastal winds during the spawning period can influence commercial fisheries catch rates. This is consistent with the relationships we found between coastal winds and the abundance of coastally spawned larval fish. However, likely due to the coarse temporal resolution of the CPUE data, there was no evidence of a positive effect of downwelling favourable winds which represent more immediate transport effects. Based on the demonstrated effects of these winds on coastal larval fish abundance, the events most likely to contribute to successful recruitment would be short periods of upwelling (to precondition the area and generate larval prey), followed by periods of onshore transport (downwelling). We propose our results are showing a negative effect of upwelling favourable winds on CPUE because offshore transport is increased during strong upwelling, which negatively affects recruitment. As our analysis is correlative rather than a manipulative experiment, the exact mechanisms underlying the relationship between upwelling favourable winds and CPUE cannot be pinpointed. Temperature mediated changes in growth and survival are likely to be a key driver of this relationship. Upwelling favourable winds cause upwelling which draws colder water up from depth (Schaeffer et al., 2013). If larvae are not advected offshore with the displaced surface water they would remain in a much cooler habitat which would likely result in slower growth, potentially increasing risk of predation (Pepin, 1991; Buckley et al., 2008). To understand possible temperature dynamics, future work should potentially consider incorporating water temperature into studies of both larval abundance and growth as well as commercial catch data.

The generally weak positive effect of drought on CPUE (with different effects in some types of estuaries) agrees with previous research using this dataset that found monthly bream CPUE increased during periods of drought (Gillson et al., 2009). Despite this, previous research also showed that the monthly CPUE of other species generally declined during periods of drought suggesting that the effect of drought on CPUE needs further investigation (Gillson et al., 2009). We 
514

515

516

517

believe the contrasting results in our study compared to Gillson et al. (2009) are the result of using different temporal scales, with shorter timescales likely more representative of changes in both fish and fisher behaviour (Gillson et al., 2009).

The sensitivity analysis conducted on the lag times between the winds and year of capture identified that the modal ages show the strongest effects of coastal winds, as would be expected with ages (represented by lags) which are less common in the harvest having smaller effect sizes. In the future, it may be possible to conduct more detailed analyses of single species by identifying bottlenecks in the lifecycle including recruitment, which may be affected by coastal winds.

\section{Historical changes in onshore winds}

Since 1850, upwelling favourable winds have increased while downwelling favourable winds have decreased in the southeast Australian region. While the direct cause of these changes is uncertain, it is possible this has been a response to global climate change. For example, intensification of surface winds have been attributed to a decline in ozone around Antarctica, which resulted in large scale changes in southern hemisphere winds including over Australia (Cai, 2006). The demonstrated changes in wind in southeast Australia would likely have reduced the onshore transport of larval fish, impacting recruitment to estuaries. Increased upwelling and decreased downwelling would increase prey availability but reduce retention near the coast, potentially transporting larvae further away from estuaries, due to similar processes as those described in Sorte (2013). This change in onshore transport may interact with the strengthening EAC which is also pushing further poleward (Suthers et al., 2011; Wu et al., 2012). If there are differences in available juvenile habitat in either cross-shelf or along-shelf directions, then the recruitment of larvae may be impacted (Sorte, 2013).

Despite this, very few fish species spawn all year round, and it is possible that seasonal changes in wind may be more important than annual changes. The temporal analysis presented here does not test alternating upwelling and downwelling favourable winds, and it would be useful to calculate a metric that encompasses the alternating nature of upwelling and downwelling favouring winds. A possible approach could be to document the number and duration of upwelling and downwelling events.

Previous research has indicated that the intensity of wind driven upwelling is likely to increase in most regions, with the exception of southwestern Africa (Bakun et al., 2010). This agrees with our finding that upwelling favourable winds have historically increased in southeast Australia. While this may result in increased fisheries production by increasing nutrient availability, it is a complex system 
in which changing winds could have a multitude of effects including increasing productivity and nutrient concentrations of source waters, regional changes in stratification and basin-scale changes in thermocline structure (Bakun et al., 2010).

551 While our study successfully combined three datasets to assess the effects of wind on larval fish retention and recruitment, it does have limitations. We used correlative analyses and several potential explanatory variables were not included in our models, which may have captured additional variance in either larval fish abundance or commercial fisheries catch rates. These include varying population spawning biomasses, water temperature, oceanographic currents, improved larval swimming ability with development or the effects of density dependence, all of which influence spawning and/or recruitment (Ottersen and Sundby, 1995; Schilling et al., 2020).

The metric of wind calculated in the present study (adjusted wind speed along certain vectors) is different to conventional analyses which typically use speed and direction vectors and directly calculate movement along an axis (e.g. Schlaefer et al., 2018). Our method applies a non-linear transformation based upon the shape of a sine wave from -1 to 1 , which results in a weaker adjustment on directions closer to the direction of interest and a harsher adjustment on more perpendicular directions. We believe this transformation is more appropriate where the coastline is not uniform but has minor deviations in orientation, relevant to the dispersal of larvae.

An important limitation of the present study was that by using a historical larval dataset, which was collected opportunistically, we could not directly quantify the movement or survival of larval fish during wind events and instead we could only look at abundances at the time of sampling while controlling for variation such as distance from coast and the individual project which collected the data. A more robust analysis would be to structure a survey that repeatedly samples in a grid pattern during wind events and directly quantifies the movement of larvae. As no larval fish size data were available, swimming ability was not considered, which is known to be an important factor influencing larval movement (Leis, 2007; Drake et al., 2018). While this could potentially bias analyses, we considered the swimming ability of larvae within each sample to be representative of a normal distribution (modelled as part of the random project effect) and any strong swimmers would have likely avoided capture by the slow plankton net. 
578

579

580

581

582

583

584

585

586

587

588

589

590

591

592

593

594

595

596

597

598

599

600

601

602

603

604

605

606

607

608

609

which can be up to 7 years in our study. This is a large time interval during which there may be many sources of mortality or population limitation. A potential limiting factor in estuaries is habitat availability, if there is insufficient suitable habitat to support recruiting larvae as juveniles, then the total population of the species will be limited by habitat rather than larval recruitment. While no information is available on potential habitat limitation in the estuaries we studied, in nearby estuaries closed to commercial fishing there is some evidence of habitat limitation (Folpp et al., 2020). The other limitation is that multiple age classes are harvested at a time and by choosing a modal age (based upon 2008-2010 harvest; Gray et al. 2015), any effects with the influence of other ages are blurred. While not possible for this study, a more rigorous approach would have been to only use the CPUE of the modal age class being harvested rather than the total CPUE. This blurring effect may be a contributor to the variation observed in the CPUE sensitivity analysis (Figure S18). The present study also did not investigate the abundance of larval fish entering estuaries (Boehlert and Mundy, 1988), which would be an important metric to confirm increased recruitment following favourable wind conditions. By expanding investigations beyond the larval period, fish recruitment mechanisms in this region might be better understood.

\section{Conclusions}

Various studies have demonstrated positive effects (Nelson et al., 1977) and negative effects (Parrish et al., 1981; Takeshige et al., 2013) of wind-driven Ekman transport of larval fish for estuarine recruitment. Despite the low variance explained in the larval fish analysis, potentially caused by the large database containing samples taken over large temporal and spatial scales, the present study is the first to show a correlation between coastal winds and fish larvae, and detect a similar corresponding effect on the commercial fishery. We suggest a recruitment mechanism involving wind-driven coastal enrichment and larval retention during the spawning season, which is evident in commercial fisheries catch rates. This mechanism involves increased productivity from wind-driven upwelling and increased retention near the coastline, which work in tandem to increase overall recruitment of larvae into estuaries. These recruitment dynamics were potentially detected in commercial estuarine fisheries data when appropriate lags are applied and by incorporating spawning period winds into recruitment models, may improve predictions of commercial fisheries catch rates. As climate change is altering wind patterns, it is likely that wind driven ocean dynamics will continue to vary and it is recommended that scientists and management consider potential changes in recruitment. 
bioRxiv preprint doi: https://doi.org/10.1101/2020.06.24.170068; this version posted July 15, 2021. The copyright holder for this preprint (which was not certified by peer review) is the author/funder, who has granted bioRxiv a license to display the preprint in perpetuity. It is made available under aCC-BY-NC 4.0 International license.

\section{0}

611 


\section{Acknowledgements}

613 This study was prompted by Dennis Reid (Australian Museum) who brought to our attention Harald

614 Dannevig's original insight on the effect of coastal winds on estuarine fisheries. Support for the $20^{\text {th }}$

615 Century Reanalysis Project version 2c dataset is provided by the U.S. Department of Energy, Office of

616 Science Biological and Environmental Research (BER), and by the National Oceanic and Atmospheric

617 Administration Climate Program Office. HTS was supported by the UNSW Network Laboratory for

618 Ocean Collaboration and NSW Research, Attraction and Acceleration Program. CH is supported by an

619 Australian Government Research Training Program Scholarship. Larval fish data were sourced from

620 the Integrated Marine Observing System (IMOS), an initiative of the Australian Government being

621 conducted as part of the National Collaborative Research Infrastructure Strategy and the Super

622 Science Initiative. This research includes computations using the computational cluster Katana

623 supported by Research Technology Services at UNSW Sydney. We thank the anonymous reviewers

624 for their constructive comments that improved this manuscript.

\section{Author contributions}

HTS, IMS, AM \& JPG collected the data, IMS conceived the ideas, HTS, CH, JPG \& AM designed the analysis, HTS performed the analysis and led the writing of the manuscript. All authors contributed critically to the drafts and gave final approval for publication.

\section{Data Availability Statement}

632 The larval fish data is freely available from the Australian Ocean Data Network

633 https://portal.aodn.org.au/ (Smith et al., 2018). The BARRA wind model is freely available upon request to the Australian Bureau of Meteorology (Su et al., 2019). $20^{\text {th }}$ Century Reanalysis V2c data provided by the NOAA/OAR/ESRL PSL, Boulder, Colorado, USA, from their Web site at https://psl.noaa.gov/ (Compo et al., 2015). NSW Commercial Fisheries Catch Data is available upon request to the NSW Department of Primary Industries Fisheries. Extracted data and code used in this analysis is available at https://github.com/HaydenSchilling/Wind-and-Fisheries. 
643

644

645

646

647

648

649

650

651

652

653

654

655

656

657

658

659

660

661

662

663

664

665

666

667

668

669

670

671

672

673

674

675

676

677

678

679

680

681

682

683

684

685

686

687

688

689

690

691

Agostini, V. N., and Bakun, A. 2002. 'Ocean triads' in the Mediterranean Sea: physical mechanisms potentially structuring reproductive habitat suitability (with example application to European anchovy, Engraulis encrasicolus). Fisheries Oceanography, 11: 129-142.

Anderson, J. 1988. A review of size dependent survival during pre-recruit stages of fishes in relation to recruitment. Journal of Northwest Atlantic Fishery Science, 8: 55-66.

Armbrecht, L. H., Roughan, M., Rossi, V., Schaeffer, A., Davies, P. L., Waite, A. M., and Armand, L. K. 2014. Phytoplankton composition under contrasting oceanographic conditions: Upwelling and downwelling (Eastern Australia). Continental Shelf Research, 75: 54-67.

Bailey, K. M., and Houde, E. D. 1989. Predation on Eggs and Larvae of Marine Fishes and the Recruitment Problem. In Advances in Marine Biology, pp. 1-83. Ed. by J. H. S. Blaxter and A. J. Southward. Academic Press.

Baird, M. E., Timko, P. G., Suthers, I. M., and Middleton, J. H. 2006. Coupled physical-biological modelling study of the East Australian Current with idealised wind forcing: Part II. Biological dynamical analysis. Journal of Marine Systems, 59: 271-291.

Bakun, A., and Weeks, S. J. 2008. The marine ecosystem off Peru: What are the secrets of its fishery productivity and what might its future hold? Progress in Oceanography, 79: 290-299.

Bakun, A., Field, D. B., Redondo-Rodriguez, A., and Weeks, S. J. 2010. Greenhouse gas, upwellingfavorable winds, and the future of coastal ocean upwelling ecosystems. Global Change Biology, 16: 1213-1228.

Boehlert, G., and Mundy, B. 1988. Roles of behavioral and physical factors in larval and juvenile fish recruitment to estuarine nursery areas. In American Fisheries Society Symposium, pp. 5167.

Brooks, S. P., and Gelman, A. 1998. General methods for monitoring convergence of iterative simulations. Journal of Computational and Graphical Statistics, 7: 434-455. Taylor \& Francis.

Bruno, D. O., Delpiani, S. M., and Acha, E. M. 2018. Diel variation of ichthyoplankton recruitment in a wind-dominated temperate coastal lagoon (Argentina). Estuarine Coastal and Shelf Science, 205: 91-99.

Buckley, L. J., Caldarone, E. M., and Clemmesen, C. 2008. Multi-species larval fish growth model based on temperature and fluorometrically derived RNA/DNA ratios: results from a metaanalysis. Marine Ecology Progress Series, 371: 221-232.

Buesa, R. J. 2019. Plankton based energy transfer rates in four Cuban coastal lagoons. Estuarine, Coastal and Shelf Science, 216: 118-127.

Burchmore, J. J., Pollard, D. A., Middleton, M. J., Bell, J. D., and Pease, B. C. 1988. Biology of four species of whiting (Pisces: Sillaginidae) in Botany Bay, NSW. Marine and Freshwater Research, 39: 709-727.

Bürkner, P.-C. 2017. brms: An R package for bayesian multilevel models using Stan. Journal of Statistical Software, 80: 1-28.

Bürkner, P.-C. 2018. Advanced bayesian multilevel modeling with the R package brms. The R Journal, 10: 395-411.

Cai, W. 2006. Antarctic ozone depletion causes an intensification of the Southern Ocean super-gyre circulation. Geophysical Research Letters, 33: L03712.

Caputi, N., Chubb, C., and Pearce, A. 2001. Environmental effects on recruitment of the western rock lobster, Panulirus cygnus. Marine and Freshwater Research, 52: 1167-1174.

Carpenter, B., Gelman, A., Hoffman, M. D., Lee, D., Goodrich, B., Betancourt, M., Brubaker, M., et al. 2017. Stan: A probabilistic programming language. Journal of Statistical Software, 76: 1-32.

Charney, N., and Record, S. 2012. vegetarian: Jost diversity measures for community data, R package version 1.3.

Ciannelli, L., Bailey, K., and Olsen, E. M. 2015. Evolutionary and ecological constraints of fish spawning habitats. ICES Journal of Marine Science, 72: 285-296. 
Collins, M. R., and Stender, B. W. 1989. Larval striped mullet (Mugil Cephalus) and white mullet (Mugil Curema) off the southeastern United States. Bulletin of Marine Science, 45: 580-589. Compo, G. P., Whitaker, J. S., Sardeshmukh, P. D., Allan, R. J., McColl, C., Yin, X., Giese, B. S., et al. 2015. NOAA/CIRES Twentieth Century Global Reanalysis Version 2c.

Cury, P. M., Fromentin, J.-M., Figuet, S., and Bonhommeau, S. 2014. Resolving Hjort's dilemma: How is recruitment related to spawning stock biomass in marine fish? Oceanography, 27: 42-47. Oceanography Society.

Dalley, E. L., Anderson, J. T., and deYoung, B. 2002. Atmospheric forcing, larval drift, and recruitment of capelin (Mallotus villosus). ICES Journal of Marine Science, 59: 929-941.

Dannevig, H. C. 1907. On some peculiarities in our coastal winds and their influence upon the abundance of fish in inshore waters. Journal of the Royal Society of NSW, 41: 27-45.

Drake, P. T., Edwards, C. A., Morgan, S. G., and Satterthwaite, E. V. 2018. Shoreward swimming boosts modeled nearshore larval supply and pelagic connectivity in a coastal upwelling region. Journal of Marine Systems, 187: 96-110.

Everett, J. D., Baird, M. E., Roughan, M., Suthers, I. M., and Doblin, M. A. 2014. Relative impact of seasonal and oceanographic drivers on surface chlorophyll a along a Western Boundary Current. Progress in Oceanography, 120: 340-351.

Folpp, H. R., Schilling, H. T., Clark, G. F., Lowry, M. B., Maslen, B., Gregson, M., and Suthers, I. M. 2020. Artificial reefs increase fish abundance in habitat-limited estuaries. Journal of Applied Ecology, 57: 1752-1761.

Garvine, R. W., Epifanio, C. E., Epifanio, C. C., and Wong, K. C. 1997. Transport and recruitment of blue crab larvae: a model with advection and mortality. Estuarine Coastal and Shelf Science, 45: 99-111.

Gasol, J. M., del Giorgio, P. A., and Duarte, C. M. 1997. Biomass distribution in marine planktonic communities. Limnology and Oceanography, 42: 1353-1363.

Gelman, A., Goodrich, B., Gabry, J., and Vehtari, A. 2019. R-squared for bayesian regression models. The American Statistician, 73: 307-309. Taylor \& Francis.

Gillson, J., Scandol, J., and Suthers, I. 2009. Estuarine gillnet fishery catch rates decline during drought in eastern Australia. Fisheries Research, 99: 26-37.

Gillson, J. 2011. Freshwater flow and fisheries production in estuarine and coastal systems: Where a drop of rain is not lost. Reviews in Fisheries Science, 19: 168-186. Taylor \& Francis.

Gillson, J. P., Maxwell, D. L., Gregory, S. D., Posen, P. E., Riley, W. D., Picken, J. L., and Assunção, M. G. L. 2020. Can aspects of the discharge regime associated with juvenile Atlantic salmon (Salmo salar L.) and trout (S. trutta L.) densities be identified using historical monitoring data from five UK rivers? Fisheries Management and Ecology, 27: 567-579.

Gray, C. A. 1993. Horizontal and vertical trends in the distributions of larval fishes in coastal waters off central New South Wales, Australia. Marine Biology, 116: 649-666.

Gray, C. A., Haddy, J. A., Fearman, J., Barnes, L. M., Macbeth, W. G., and Kendall, B. W. 2012. Reproduction, growth and connectivity among populations of Girella tricuspidata (Pisces: Girellidae). Aquatic Biology, 16: 53-68.

Gray, C. A., Young, C. L., Johnson, D. D., and Rotherham, D. 2015. Integrating fishery-independent and -dependent data for improved sustainability of fisheries resources and other aspects of biodiversity. Sydney, Australia.

Gray, C. A., and Barnes, L. M. 2015. Spawning, maturity, growth and movement of Platycephalus fuscus (Cuvier, 1829) (Platycephalidae): fishery management considerations. Journal of Applied Ichthyology, 31: 442-450.

Gray, C. A., Miskiewicz, A. G., Otway, N. M., and Kingsford, M. J. 2019. Historical daytime vertical structure of larval fish assemblages in southeast Australian coastal waters: A benchmark for examining regional ecosystem change. Regional Studies in Marine Science, 29: 100634.

Griffin, D. A., and Middleton, J. H. 1992. Upwelling and internal tides over the inner New South Wales continental shelf. Journal of Geophysical Research: Oceans, 97: 14389-14405. 
Haggarty, D. R., and King, J. R. 2006. CPUE as an index of relative abundance for nearshore reef fishes. Fisheries Research, 81: 89-93.

Hare, J., and Govoni, J. 2005. Comparison of average larval fish vertical distributions among species exhibiting different transport pathways on the southeast United States continental shelf. Fishery Bulletin, 103: 728-736.

Harley, S. J., Myers, R. A., and Dunn, A. 2001. Is catch-per-unit-effort proportional to abundance? Canadian Journal of Fisheries and Aquatic Sciences. NRC Research Press Ottawa, Canada. https://cdnsciencepub.com/doi/abs/10.1139/f01-112 (Accessed 18 March 2021).

Hatzinger, R., Hornik, K., Nagel, H., and Maier, M. J. 2015. Companion to: In R: Einführung durch angewandte Statistik, 2nd Edition. Pearson Studium, München.

Helbig, J. A., and Pepin, P. 1998. Partitioning the influence of physical processes on the estimation of ichthyoplankton mortality rates. I. Theory. Canadian Journal of Fisheries and Aquatic Sciences, 55: 2189-2205.

Hijmans, R. J. 2019. raster: Geographic data analysis and modeling, R package version 3.0.2.

Hinchliffe, C., Smith, J. A., Everett, J. D., Falster, D. S., Lara-Lopez, A., Miskiewicz, A. G., Richardson, A. J., et al. 2021. Modelling the distribution of larval fish in a western boundary current using a multi-voyage database. Reviews in Fish Biology and Fisheries, 31: 399-415.

Houde, E. D. 2008. Emerging from Hjort's shadow. Journal of Northwest Atlantic Fishery Science, 41: 53-70.

Ings, D. W., Gregory, R. S., and Schneider, D. C. 2008. Episodic downwelling predicts recruitment of Atlantic cod, Greenland cod and white hake to Newfoundland coastal waters. Journal of Marine Research, 66: 529-561.

Kell, L. T., Nash, R. D. M., Dickey-Collas, M., Mosqueira, I., and Szuwalski, C. 2016. Is spawning stock biomass a robust proxy for reproductive potential? Fish and Fisheries, 17: 596-616.

Leis, J. M. 2007. Behaviour as input for modelling dispersal of fish larvae: behaviour, biogeography, hydrodynamics, ontogeny, physiology and phylogeny meet hydrography. Marine Ecology Progress Series, 347: 185-193.

Lüdecke, D. 2018. ggeffects: Tidy data frames of marginal effects from regression models. Journal of Open Source Software, 3: 772.

Lüdecke, D., Makowski, D., Waggoner, P., and Patil, I. 2020. performance: Assessment of regression models performance, R package version 0.5.0. https://easystats.github.io/performance/.

McClean-Padman, J., and Padman, L. 1991. Summer upwelling on the Sydney inner continental shelf: The relative roles of local wind forcing and mesoscale eddy encroachment. Continental Shelf Research, 11: 321-345.

McFarlane, G. A., and Beamish, R. J. 1992. Climatic Influence Linking Copepod Production with Strong Year-Classes in Sablefish, Anoplopoma fimbria. Canadian Journal of Fisheries and Aquatic Sciences, 49: 743-753.

Middleton, J. H., Cox, D., and Tate, P. 1996. The oceanography of the Sydney region. Marine Pollution Bulletin, 33: 124-131.

Neira, F. J., Miskiewicz, A. G., and Trnski, T. 1998. Larvae of temperate Australian fishes: laboratory guide for larval fish identification. UWA Publishing.

Nelson, W. R., Ingham, M. C., and Schaaf, W. E. 1977. Larval transport and year-class strength of Atlantic menhaden, Brevoortia tyrannus. Fishery Bulletin, 75: 23-41.

Ochwada-Doyle, F., Roberts, D., Gray, C., Barnes, L., Haddy, J., and Fearman, J. 2012. Characterizing the biological traits and life history of Acanthopagrus (Sparidae) hybrid complexes: implications for conservation and management. Journal of Fish Biology, 81: 1540-1558.

Oke, P. R., Roughan, M., Cetina-Heredia, P., Pilo, G. S., Ridgway, K. R., Rykova, T., Archer, M. R., et al. 2019. Revisiting the circulation of the East Australian Current: Its path, separation, and eddy field. Progress in Oceanography, 176: 102139. 
Ospina-Alvarez, A., Weidberg, N., Aiken, C. M., and Navarrete, S. A. 2018. Larval transport in the upwelling ecosystem of central Chile: The effects of vertical migration, developmental time and coastal topography on recruitment. Progress in Oceanography, 168: 82-99.

Ottersen, G., and Sundby, S. 1995. Effects of temperature, wind and spawning stock biomass on recruitment of Arcto-Norwegian cod. Fisheries Oceanography, 4: 278-292.

Parrish, R. H., Nelson, C. S., and Bakun, A. 1981. Transport mechanisms and reproductive success of fishes in the California Current. Biological Oceanography, 1: 175-203.

Payne, N. L., van der Meulen, D. E., Gannon, R., Semmens, J. M., Suthers, I. M., Gray, C. A., and Taylor, M. D. 2013. Rain reverses diel activity rhythms in an estuarine teleost. Proceedings of the Royal Society B: Biological Sciences, 280: 20122363. Royal Society.

Pease, B. C. 1999. A spatially oriented analysis of estuaries and their associated commercial fisheries in New South Wales, Australia. Fisheries Research, 42: 67-86.

Pepin, P. 1991. Effect of temperature and size on development, mortality, and survival rates of the pelagic early life history stages of marine fish. Canadian Journal of Fisheries and Aquatic Sciences, 48: 503-518.

Pepin, P. 2016. Reconsidering the impossible - linking environmental drivers to growth, mortality, and recruitment of fish. Canadian Journal of Fisheries and Aquatic Sciences, 73: 205-215.

Pierce, D. 2019. ncdf4: Interface to unidata netCDF (Version 4 or earlier) format data files, R package version 1.17.

R Core Team. 2020. R: A language and environment for statistical computing v4.0.2. R Foundation for Statistical Computing, Vienna, Austria.

Richards, L. J., and Schnute, J. T. 1986. An experimental and statistical approach to the question: Is CPUE an index of abundance? Canadian Journal of Fisheries and Aquatic Sciences. NRC Research Press Ottawa, Canada. https://cdnsciencepub.com/doi/abs/10.1139/f86-151 (Accessed 19 March 2021).

Roughan, M., and Middleton, J. H. 2002. A comparison of observed upwelling mechanisms off the east coast of Australia. Continental Shelf Research, 22: 2551-2572.

Roughan, M., Macdonald, H. S., Baird, M. E., and Glasby, T. M. 2011. Modelling coastal connectivity in a Western Boundary Current: Seasonal and inter-annual variability. Deep Sea Research Part II: Topical Studies in Oceanography, 58: 628-644.

Roy, P. S., Williams, R. J., Jones, A. R., Yassini, I., Gibbs, P. J., Coates, B., West, R. J., et al. 2001. Structure and Function of South-east Australian Estuaries. Estuarine, Coastal and Shelf Science, 53: 351-384.

Rykaczewski, R. R., and Checkley, D. M. 2008. Influence of ocean winds on the pelagic ecosystem in upwelling regions. Proceedings of the National Academy of Sciences of the United States of America, 105: 1965-1970.

Santos, A. M. P., Peliz, A., Dubert, J., Oliveira, P. B., Angélico, M. M., and Ré, P. 2004. Impact of a winter upwelling event on the distribution and transport of sardine (Sardina pilchardus) eggs and larvae off western Iberia: a retention mechanism. Continental Shelf Research, 24: 149165.

Schaeffer, A., Roughan, M., and Morris, B. D. 2013. Cross-shelf dynamics in a western boundary current regime: Implications for upwelling. Journal of Physical Oceanography, 44: 28122813.

Schaeffer, A., Roughan, M., and Wood, J. E. 2014. Observed bottom boundary layer transport and uplift on the continental shelf adjacent to a western boundary current. Journal of Geophysical Research-Oceans, 119: 4922-4939.

Schielzeth, H. 2010. Simple means to improve the interpretability of regression coefficients. Methods in Ecology and Evolution, 1: 103-113.

Schilling, H. T., Everett, J. D., Smith, J. A., Stewart, J., Hughes, J. M., Roughan, M., Kerry, C., et al. 2020. Multiple spawning events promote increased larval dispersal of a predatory fish in a western boundary current. Fisheries Oceanography, 29: 309-323. 
Schlaefer, J. A., Wolanski, E., Lambrechts, J., and Kingsford, M. J. 2018. Wind conditions on the Great Barrier Reef influenced the recruitment of snapper (Lutjanus carponotatus). Frontiers in Marine Science, 5. Frontiers.

Smith, J. A., Miskiewicz, A. G., Beckley, L. E., Everett, J. D., Garcia, V., Gray, C. A., Holliday, D., et al. 2018. A database of marine larval fish assemblages in Australian temperate and subtropical waters. Scientific Data, 5: 180207.

Sorte, C. J. B. 2013. Predicting persistence in a changing climate: flow direction and limitations to redistribution. Oikos, 122: 161-170.

Stewart, J., Hegarty, A.-M., Young, C., and Fowler, A. M. 2018. Sex-specific differences in growth, mortality and migration support population resilience in the heavily exploited migratory marine teleost Mugil cephalus (Linnaeus 1758). Marine and Freshwater Research, 69: 385394.

Su, C.-H., Eizenberg, N., Steinle, P., Jakob, D., Fox-Hughes, P., White, C. J., Rennie, S., et al. 2019. BARRA v1.0: the Bureau of Meteorology Atmospheric high-resolution Regional Reanalysis for Australia. Geoscientific Model Development, 12: 2049-2068.

Su, C.-H., Eizenberg, N., Jakob, D., Fox-Hughes, P., Steinle, P., White, C. J., and Franklin, C. 2020. BARRA v1.0: Kilometre-scale downscaling of an Australian regional atmospheric reanalysis over four midlatitude domains. Geoscientific Model Development Discussions [Preprint]: 134. Copernicus $\mathrm{GmbH}$.

Suthers, I. M., Everett, J. D., Roughan, M., Young, J. W., Oke, P. R., Condie, S. A., Hartog, J. R., et al. 2011. The strengthening East Australian Current, its eddies and biological effects - an introduction and overview. Deep-Sea Research Part II-Topical Studies in Oceanography, 58: 538-546.

Suthers, I. M., Reid, D. D., Moksness, E., and Schilling, H. T. 2020. Novel fisheries investigations by Harald Dannevig: some parallels with Johan Hjort on the other side of the world. ICES Journal of Marine Science.

Sydeman, W. J., García-Reyes, M., Schoeman, D. S., Rykaczewski, R. R., Thompson, S. A., Black, B. A., and Bograd, S. J. 2014. Climate change and wind intensification in coastal upwelling ecosystems. Science, 345: 77-80.

Szuwalski, C. S., Vert-Pre, K. A., Punt, A. E., Branch, T. A., and Hilborn, R. 2015. Examining common assumptions about recruitment: a meta-analysis of recruitment dynamics for worldwide marine fisheries. Fish and Fisheries, 16: 633-648.

Takeshige, A., Miyake, Y., Nakata, H., Kitagawa, T., and Kimura, S. 2013. Effect of wind stress on the catch of Japanese anchovy Engraulis japonicus off northwestern Kyushu, Japan. Fisheries Science, 79: 989-998.

van der Linden, S., and Chryst, B. 2017. No Need for Bayes Factors: A Fully Bayesian Evidence Synthesis. Frontiers in Applied Mathematics and Statistics, 3. Frontiers. https://www.frontiersin.org/articles/10.3389/fams.2017.00012/full (Accessed 9 November 2020).

Wickham, H. 2017. tidyverse: Easily install and load the 'Tidyverse'.

Wilhelm, M. R., Painting, S. J., Field, J. G., Kerstan, M., Durholtz, M. D., Wilhelm, M. R., Painting, S. J., et al. 2005. Impact of environmental factors on survival of larval and juvenile Cape anchovy Engraulis encrasicolus (G.) in the southern Benguela upwelling region, determined from hatchdate distributions: implications for recruitment. Marine and Freshwater Research, 56: 561-572. CSIRO PUBLISHING.

Wilson, M. T., and Laman, N. 2021. Interannual variation in the coastal distribution of a juvenile gadid in the northeast Pacific Ocean: The relevance of wind and effect on recruitment. Fisheries Oceanography, 30: 3-22.

Wu, L., Cai, W., Zhang, L., Nakamura, H., Timmermann, A., Joyce, T., McPhaden, M. J., et al. 2012. Enhanced warming over the global subtropical western boundary currents. Nature Climate Change, 2: 161-166. Nature Publishing Group. 
bioRxiv preprint doi: https://doi.org/10.1101/2020.06.24.170068; this version posted July 15, 2021. The copyright holder for this preprint

(which was not certified by peer review) is the author/funder, who has granted bioRxiv a license to display the preprint in perpetuity. It is made available under aCC-BY-NC 4.0 International license.

894

895

896

897

Zenitani, H., Kono, N., and Tsukamoto, Y. 2007. Relationship between daily survival rates of larval Japanese anchovy (Engraulis japonicus) and concentrations of copepod nauplii in the Seto Inland Sea, Japan. Fisheries Oceanography, 16: 473-478. 
Table 1 Details of the spawning season and modal age of capture in gillnet fisheries for four coastally

900 spawning fish species, used to define the choice of lags for winds during the spawning season with

901 an example of the wind intervals used for the annual catch-per-unit-effort (CPUE) between July 1997

902 and June 1998. The ranges of harvested ages (> $5 \%$ of the catch) is shown in brackets with the modal harvested age. Full age distributions can be seen in Gray et al. (2015).

\begin{tabular}{|c|c|c|c|}
\hline Species & Spawning season & $\begin{array}{c}\text { Modal } \\
\text { harvested age } \\
\text { (Range; Gray et } \\
\text { al., 2015) }\end{array}$ & $\begin{array}{c}\text { Example wind } \\
\text { intervals used for } \\
\text { annual CPUE for July } \\
1997 \text { - June } 1998\end{array}$ \\
\hline $\begin{array}{c}\text { bream } \\
\text { (Acanthopagrus } \\
\text { australis) }\end{array}$ & $\begin{array}{l}\text { October - February (Ochwada-Doyle } \\
\text { et al., 2012) }\end{array}$ & $7(4-11)$ & $\begin{array}{l}\text { October } 1989 \text { - } \\
\text { February } 1990\end{array}$ \\
\hline $\begin{array}{l}\text { dusky flathead } \\
\text { (Platycephalus } \\
\text { fuscus) }\end{array}$ & $\begin{array}{c}\text { December - March (Gray and } \\
\text { Barnes, 2015) }\end{array}$ & $3(2-5)$ & $\begin{array}{l}\text { December } 1993 \text { - } \\
\text { March } 1994\end{array}$ \\
\hline $\begin{array}{l}\text { sand whiting } \\
\text { (Sillago ciliata) }\end{array}$ & $\begin{array}{c}\text { December - February (Burchmore et } \\
\qquad \text { al., 1988) }\end{array}$ & $6(3-10)$ & $\begin{array}{l}\text { December } 1991 \text { - } \\
\text { February } 1992\end{array}$ \\
\hline $\begin{array}{c}\text { sea mullet } \\
\text { (Mugil cephalus) }\end{array}$ & April - July (Stewart et al., 2018) & $2(1-5)$ & April - July 1995 \\
\hline
\end{tabular}

904

905

906 
bioRxiv preprint doi: https://doi org/10.1101/2020.06 24.170068; this version posted July 15, 2021. The copyright holder for this preprint

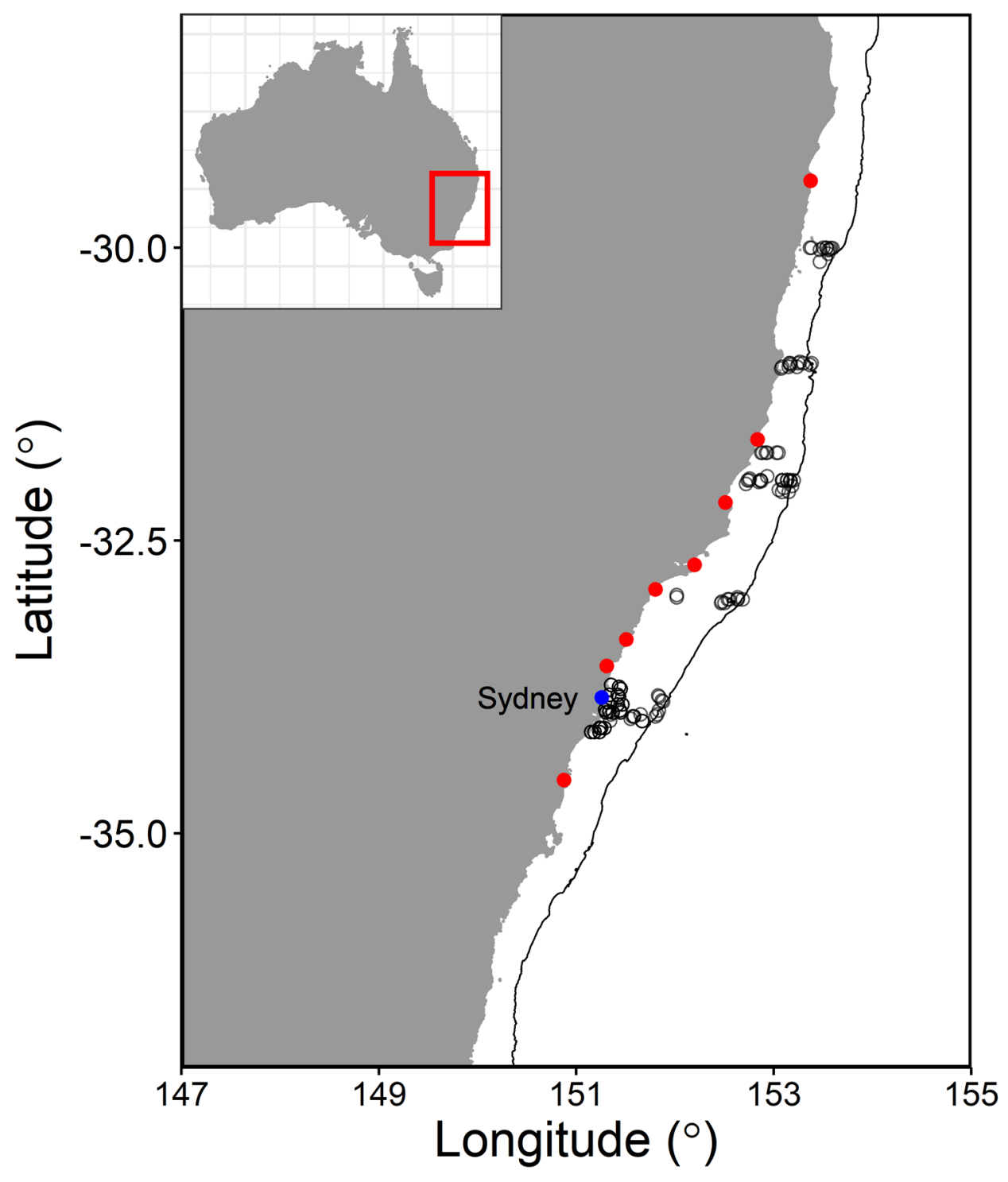

909 Figure 1 Location of southeast Australia showing the position of the larval fish samples included in 910 the study (empty grey circles), the estuaries used in the catch-per-unit-effort analysis (filled red 911 circles) and Sydney (filled blue circle). The black line represents the $1000 \mathrm{~m}$ isobath. 


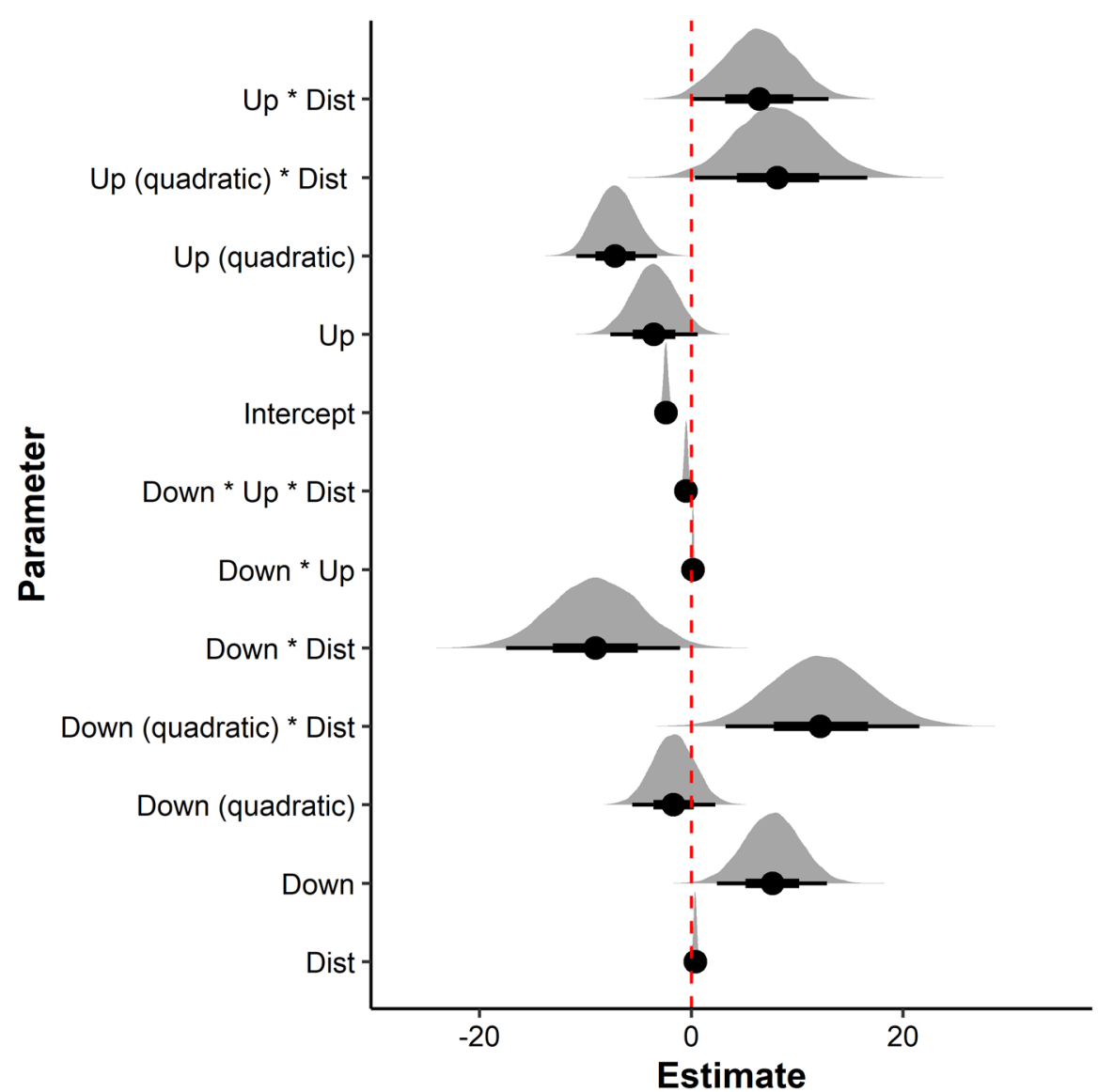

914 Figure 2 Caterpillar plots showing the Bayesian parameter estimates for the coastally spawned larval

915 fish abundance models based upon winds in the 14 days prior to sampling. Points show the estimate

916 of the parameter with the horizontal bar representing the $66 \%$ (thick bar) and $95 \%$ (thin bar)

917 credible interval of the estimate. Model terms include distance-to-coast (Dist), upwelling favourable

918 winds (Up) and downwelling favourable winds (Down). Parameter estimates are deemed important

919 if the $95 \%$ credible interval does not cross the dashed red line which marks an estimate of zero. For

920 exact estimate values see Table S3.

921

922

923

924

925 


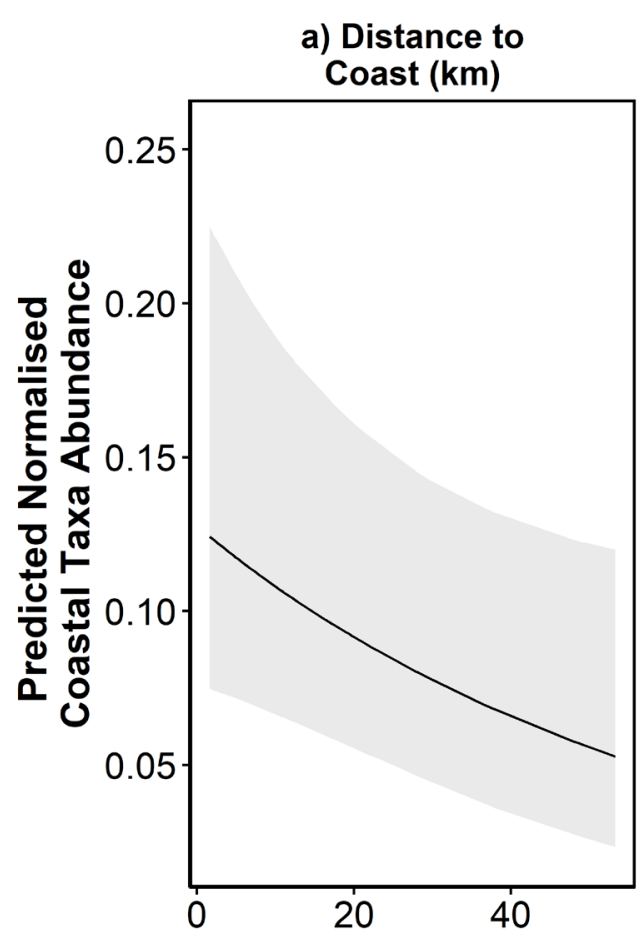

b) Upwelling Favourable Winds

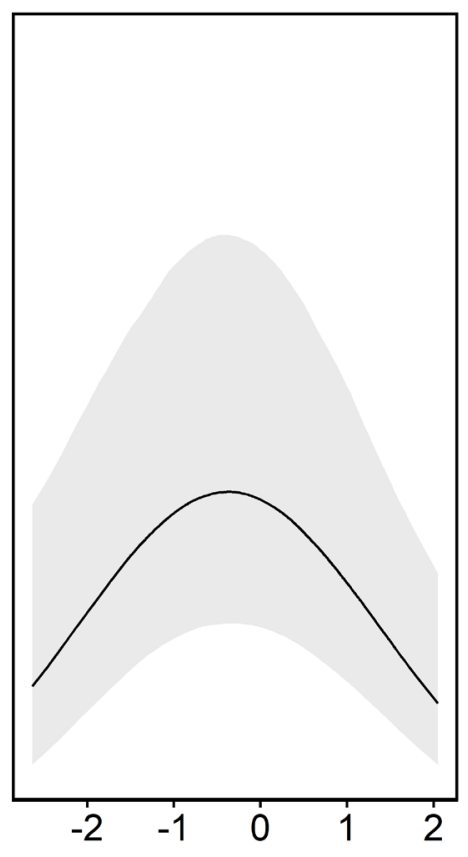

c) Downwelling Favourable Winds

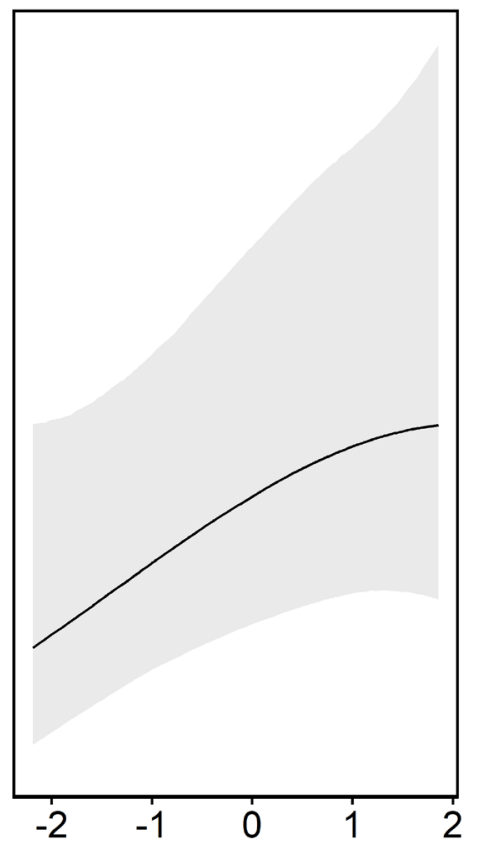

928 Figure 3 Visualisation of the predicted normalised coastal larval abundance based on the generalised

929 linear mixed model for winds 14 days prior to sampling: a) the effect of distance from the coast,

930 based upon mean ( 0 on the standardised scale) upwelling and downwelling favourable winds with shading showing the $95 \%$ credible interval; b) the effect of upwelling favourable winds; and c) the effect of downwelling favourable winds. Predictions for each variable were made while holding all other variables within the model to mean values ( 0 for wind variables and $10 \mathrm{~km}$ for distance from the coast). For the winds, 0 represents mean winds, with 1 and -1 representing 1 and -1 SD from the mean, respectively. 


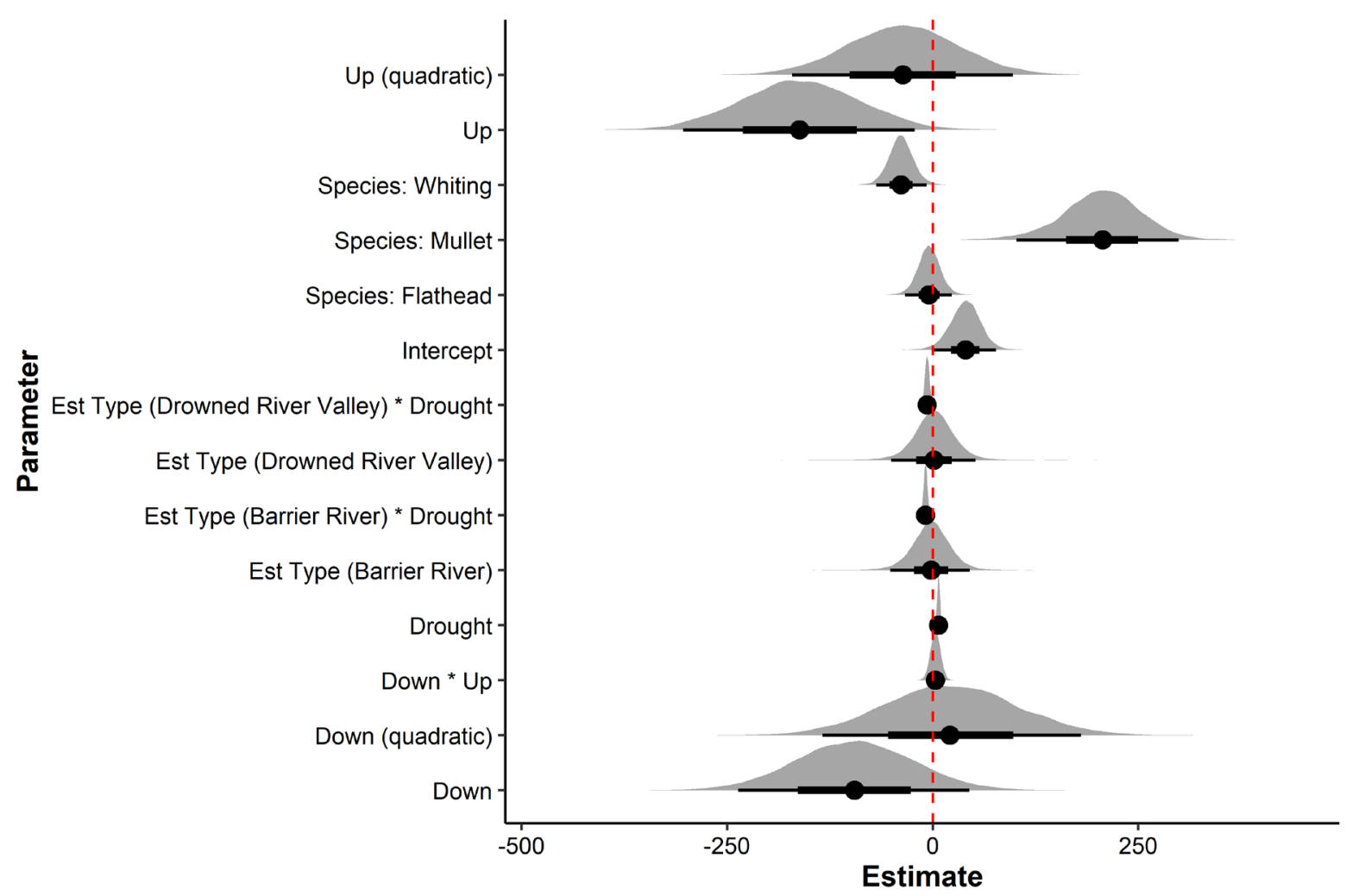

940 Figure 4 Caterpillar plot showing the Bayesian parameter estimates for the multi-species catch-per-

941 unit-effort (CPUE) generalised linear mixed model. Model terms include upwelling favourable winds

942 (Up), downwelling favourable winds (Down) and estuary type (Est Type). Points show the estimate of

943 the parameter with the horizontal bar representing the 66\% (thick bar) and 95\% (thin bar) credible

944 intervals $(\mathrm{Cl})$ of the estimate. The dashed red line marks an estimate of zero. The $95 \% \mathrm{Cl}$ does not

945 cross zero for Up Winds, Species: Whiting, Species: Mullet, Drought Months, Estuary Type: Drowned

946 River Valley * Drought Months and Estuary Type: Barrier River * Drought Months. For exact estimate

947 values see Table S4. 


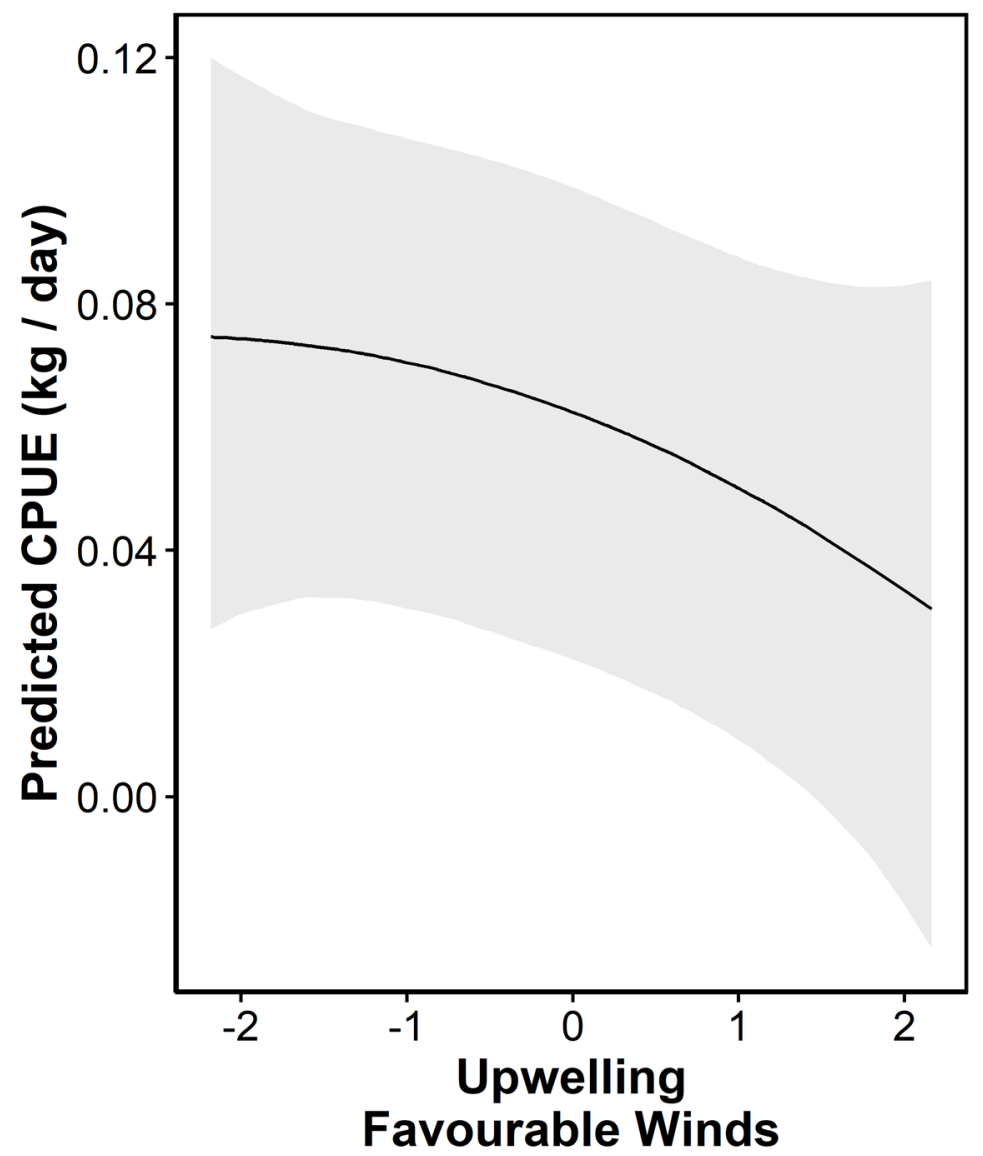

949 Figure 5 Visualisation of predicted catch-per-unit-effort (CPUE) based upon upwelling favourable

950 winds during the spawning period as predicted by the results of the CPUE Bayesian linear mixed

951 model. The grey area represents the $95 \%$ credible interval. There were no detectable effects of

952 downwelling favourable winds and the effects of drought are shown in the supplementary material

953 (Figure S17). Predictions were made while holding all other variables within the model to mean

954 values. Note due to the random slope and intercept effects in the model, the actual y scale is

955 relative. 
a) Upwelling Favourable Winds

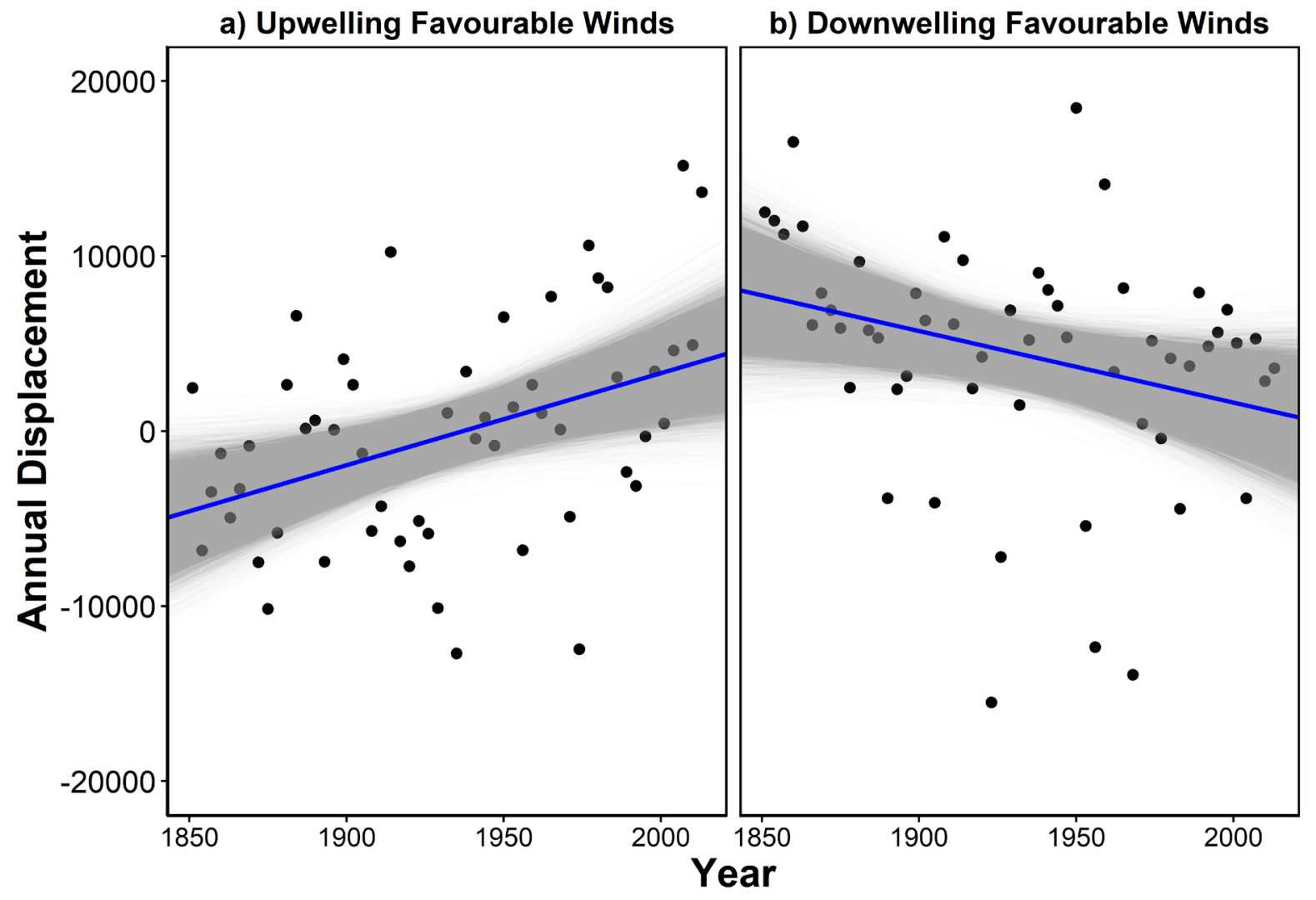

958

Figure 6 Temporal change in annual net displacement in upwelling (from northeast; Estimate of

960 annual change: $52.86,95 \%$ credible interval: $19.00-85.59$ ) and downwelling favourable winds (from

961 southeast; Estimate of annual change: $-40.93,95 \%$ credible interval: $-78.18--3.71$ ) between 1850

962 and 2014. The grey lines show 20,000 posterior sample estimates with the median trend line in blue.

963 Only every third year of annual net displacement data was included in the models to account for

964 temporal autocorrelation in the wind time-series data. 